\title{
What could the entire cornstover contribute to the enhancement of waste activated sludge acidification? Performance assessment and microbial community analysis
}

\author{
Aijuan Zhou ${ }^{1,2^{*}}$, Jiaguang Zhang ${ }^{3}$, Kaili Wen ${ }^{1}$, Zhihong Liu' ${ }^{1}$, Guoying Wang ${ }^{1}$, Wenzong Liu ${ }^{4}$, Aijie Wang ${ }^{4,5}$ \\ and Xiuping Yue ${ }^{1^{*}}$
}

\begin{abstract}
Background: Volatile fatty acids (VFAs) production from waste activated sludge (WAS) digestion is constrained by unbalanced nutrient composition (low carbon-to-nitrogen ratio). Characteristics conditioning by extra carbon sources, normally in the mixture of raw solid, has been reported to be an efficient approach to enhance WAS acidification. However, little attention has been paid to the contributions of other adjustment forms. Moreover, the corresponding ecological estimation has not been investigated yet.

Results: In this study, the feasibility of corn stover (CS) conditioning with three adjustment forms [pretreated straw $(\mathrm{S})$, hydrolysate $(\mathrm{H})$ and hydrolysate + straw $(\mathrm{HS})$ ] in improving VFAs production from WAS was demonstrated. It was observed that the highest VFAs yield was achieved in $\mathrm{H}$ co-digesting test (574 mg COD/g VSS), while it was only $392 \mathrm{mg}$ COD/g VSS for WAS digesting alone. VFAs composition was strongly adjustment form-dependent, as more acetic (HAc) and propionic (HPr) acids were generated in CS_HS and S, respectively. High-throughput sequencing analysis illustrated that acid (especially HAc)-producing characteristic genera (Bacteroides, Proteiniclasticum and Fluviicola) and HPr-producing characteristic genera (Mangroviflexus and Paludibacter) were detected by CS_HS and S conditioning, respectively.

Conclusions: Corn stover conditioning greatly upgraded the WAS acidification performance, especially for the CS_H adjustment form, and the VFAs yield gained was considerably larger than that previously reported. CS adjustment forms played an important role in structuring the innate microbial community in WAS. Canonical correlation analysis illustrated that characteristic genera, with better hydrolysis and acidification abilities, could be enriched by the feedstocks with certain content of cellulose, hemicellulose or their saccharification hydrolysates. Moreover, ecological estimation revealed that, as far as the entire CS (including $S$ and $\mathrm{H}$ ) per acre was concerned, the capacity of WAS treatment would reach that produced in a one million mts capacity wastewater treatment plants (WWTPs) per day. These findings may have crucial implications for the operation of WWTPs.
\end{abstract}

Keywords: Waste activated sludge (WAS), Corn straw (CS), Adjustment form, Volatile fatty acids (VFAs), Anaerobic digestion, Ecological estimation

\footnotetext{
*Correspondence: zhouaijuan@tyut.edu.cn; yuexiuping@tyut.edu.cn

${ }^{1}$ College of Environmental Science and Engineering, Taiyuan University

of Technology, 030024 Taiyuan, China

Full list of author information is available at the end of the article
} 


\section{Background}

As the by-product of wastewater treatment plants (WWTPs), 6.25 million tons of dry waste activated sludge (WAS) was produced in China in 2013, which is considered as an inevitable drawback inherent to activated sludge processes [1]. The cost of treating and disposing WAS takes $40-60 \%$ of the total costs for WWTPs [2]. With the conventional disposal routes coming under pressure, more cost-effective and environmentally benign alternatives for WAS are needed. Currently, due to its carbonaceous characteristics (organics possess 90-95\% in dry weight), WAS is considered as a renewable and utilizable biomass resource and gained worldwide attention [3-5]. Cost-effective microbial conversion from WAS by anaerobic digestion to specific valuable products is an innovative and promising way to gain social and economic benefits.

As the most important intermediate, volatile fatty acids (VFAs) production from WAS digestion has been proven to be a feasible and effective carbon resource recovery process $[6,7]$. Compared with time-consuming conventional energy-rich methane production (20-30 days) and the low degradation efficiency of the dry organic solids (30-50\%) from WAS [8], VFAs-producing processes with proper pretreatments are completed in a relatively short operation cycle (3-8 days). Moreover, VFAs are a good choice of extra carbon for many bioprocesses, especially for biological nutrients removal (BNR) [9]. Available biodegradable carbon is required to promote the growth of denitrifying bacteria and phosphorus accumulating organisms over competing organisms. In addition, WAS contains a significant amount of embedded energy, on the order of $20 \mathrm{MJ} / \mathrm{kg}$ of dry sludge. By practicing energy recovery from WAS, the produced methane, which is clean and renewable, can be used as a substitute for fossil fuels and oil to some extent. Moreover, accumulation of VFAs was an important factor that influenced biogas generation in two-stage anaerobic digestion [10]. Regarding the way to utilize VFAs, undeniably, it mainly depends on the composition of the produced VFAs [45]. Aiming to strengthen the performance of WAS acidification, many approaches involving pretreatments (e.g., physical, chemical or biological methods) and optimizing operating conditions (e.g., $\mathrm{pH}$, temperature, mixing and solids retention time) have thus been developed $[8,11$, 12].

Pretreatment is a prerequisite to enhance the hydrolysis of particulate organic matter, either enclosed inside the microbial cell or enmeshed in an extracellular polymeric matrix, to soluble substrates in WAS [13]. Nevertheless, VFAs yield is still limited by the unbalanced nutrient component, especially the low carbon-to-nitrogen ratio $(\mathrm{C} / \mathrm{N}$ ratio: $\sim 6.0)$, caused by the large amount of proteins in WAS. This unbalanced situation results in the inefficient conversion of complex organic matter. It is concluded that the suggested $\mathrm{C} / \mathrm{N}$ ratio for anaerobic sludge digestion is 20-30 [14]. The organic solid waste with a high carbon content is, therefore, suitable for being treated with WAS possessing high nitrogen content to obtain a nutrient balance. Previous research showed that conditioning with carbon-rich municipal solid wastes, agricultural residues, or industrial wastes have been reported as a cost-effective solution for the production of VFAs [15-17]. Lignocellulose is considered as an attractive raw material for the production of VFAs from co-digestion with WAS because of its availability in large quantities at low cost $[18,19]$. In China, corn stover (CS) is one of the most abundant agricultural wastes [20]. CS consists of high contents of cellulose, hemicellulose and a relatively low content of lignin [21]. Recent studies have portrayed that the presence of cellulose and hemicellulose in the pretreated lignocellulose residues lead to an apparent improvement in WAS acidification, and this, in turn, may affect the composition and metabolism activity of fermentation bacteria [18]. However, a large amount of monomeric sugars (e.g., glucose, xylose and arabinose) are present in the CS hydrolysates. It is also an ideal feedstock for the carbohydrate substrate in the conversion of WAS to VFAs. It is crucial to investigate the vital roles of different CS conditioning forms on WAS acidification and the effects that will be produced on the VFAs composition and metabolism activity of fermentation bacteria. Moreover, to provide a sound basis for cost-efficient biomass stabilization and bioenergy recovery applied in WWTPs, it is important to know what the entire CS could bring for the VFAs recovery from WAS digestion.

Anaerobic digestion generally requires multiple groups of microorganisms working together to transform primary substrates to energy or high-valued chemicals [22, 23]. Previous studies showed that microbial community functional structure played an important role in bioreactor performance [22, 24, 25]. In this sense, understanding microbial behavior and interactions is essential to improve the fermentation process. Additional exploration of the microbial communities will allow engineers and researchers to establish more direct cause-andeffect relationships between community structure and function. Based on the considerations above, we investigated the VFAs production from WAS digestion by CS conditioning, with three adjustment forms (e.g., straw, hydrolysate, hydrolysate + straw), by means of process assessment associated with microbial community response analysis. We monitored the performances of hydrolysis, acidification and methanogenesis during WAS and CS co-digestion. Shifts of the acidification spectrum from WAS by conditioning with different 
CS forms were studied. Furthermore, we also examined the related functional microbial community structures, using high-throughput pyrosequencing of the 16S rRNA gene. Correlations between environmental variables and microbial populations were assessed, using canonical correspondence analysis (CCA).

\section{Methods}

\section{Characteristics and pretreatment procedure of substrates}

Waste activated sludge was collected from the Jinzhong municipal wastewater treatment plant (Taiyuan City, China) and concentrated by settling at $4{ }^{\circ} \mathrm{C}$ for $24 \mathrm{~h}$. Prior to its use as feed, WAS was screened with a $1 \mathrm{~mm}$ sieve to remove impurities to prevent clogging problems. Ultrasonic pretreatment of WAS was performed with a $28+40 \mathrm{kHz}$ ultrasonicator; other operation parameters were documented in a previous publication [19]. The main characteristics (average value plus standard deviation of three tests) of the concentrated and pretreated WAS are displayed in Additional file 1: Table S1.

CS used in this study was collected at Taiyuan City, Shanxi Province, China. The chopped CS was dried in the oven at $70{ }^{\circ} \mathrm{C}$ until constant weight. Then, it was milled to $2-10 \mathrm{~mm}$ before storing at room temperature prior to the tests. Alkaline pretreatment of CS was performed in a thermostatic water bath at $85{ }^{\circ} \mathrm{C}$ with a solid-liquid ratio of $1: 10$ ( $\mathrm{g}$ dry weight to $\mathrm{mL}$ ). The $\mathrm{NaOH}$ concentration was $2 \%(\mathrm{w} / \mathrm{w})$ and the residence time was $1 \mathrm{~h}$. The main compositions of raw and pretreated CS on a dry basis were 36 and $65 \%$ cellulose, 23 and $13 \%$ hemicellulose and 14 and $5 \%$ lignin, respectively. The CS hydrolysate contained $2.8 \mathrm{~g} / \mathrm{L}$ glucose, $5.5 \mathrm{~g} / \mathrm{L}$ xylose and $1.0 \mathrm{~g} / \mathrm{L}$ arabinose. The volatile solids content was $0.84 \mathrm{~g}$ volatile solids/g dry solids. The solid residue was separated by centrifugation $(10,000 \mathrm{rpm}(9392 \times g), 10 \mathrm{~min})$ (Sigma $3 \mathrm{~K} 30$, Germany) and then dried at $70{ }^{\circ} \mathrm{C}$ to a constant weight and milled to $1-2 \mathrm{~mm}$. The pretreated CS residue and supernatant were added for balancing the $\mathrm{C} / \mathrm{N}$ radio of WAS fermentation.

\section{Experimental setup and operations}

Batch experiments were carried out in twenty-one batch reactors. These reactors, with $300 \mathrm{~mL}$ of the mixed substrates each, were divided into seven groups (three reactors as replicates for each group). The feedstock for one group was only the ultrasonic pretreated WAS (hereinafter referred to as the control test). Two groups were fed with the mixtures of pretreated WAS and pretreated straw, with CS proportion of 50 and 35\% (hereinafter referred to as the 50:50\%_S and 65:35\%_S tests). Two groups were fed with the mixtures of pretreated WAS and CS hydrolysate (hereinafter referred to as the 50:50\%_H and 65:35\%_H tests), the amounts of which were in accordance with the above straw tests. The feedstocks for the remaining two groups were the mixtures of pretreated WAS and CS, both hydrolysate and straw (hereinafter referred to as the 50:50\%_HS and 65:35\%_HS tests). After flushing with nitrogen gas to remove oxygen, all bottles were capped, sealed, and stirred in an air-bath shaker (100 rpm) at $35 \pm 1{ }^{\circ} \mathrm{C}$.

\section{DNA extraction and pyrosequencing}

Before DNA extraction, sludge samples were centrifuged at $8000 \mathrm{~g}$ to remove the supernatant. DNA was extracted from the sludge sediments of three replicate reactors using a Soil DNA Isolation Kit (Sangon Biotech Co., Ltd.), according to the manufacturer's instructions, and then it was pooled together. Amplicon liberates were constructed for pyrosequencing using the bacterial fused primers $341 \mathrm{~F}$ and $805 \mathrm{R}$ for the $\mathrm{V} 3-\mathrm{V} 4$ region of the $16 \mathrm{~S}$ rRNA gene. To achieve the sample multiplexing during pyrosequencing, barcodes were incorporated between the adaptor and forward primer. The procedure of polymerase chain reaction (PCR) was performed in our previous study [26]. After being purified and quantified, the PCR amplicon was used for pyrosequencing on an Illumina MiSeq. The raw sequences were deposited in the NCBI Short Read Archive database with accession no. SRR3602034. The adapters, barcodes, and primers in all raw sequences were trimmed to minimize the effects of random sequencing errors. Sequences shorter than $350 \mathrm{bp}$, or containing any ambiguous base calls, were removed.

The remaining sequences were clustered into operational taxonomic units (OTUs), using the $97 \%$ identity threshold (3\% dissimilarity level). Alpha diversity measurements, including Shannon and Chao1 indices were calculated for each sample. Beta diversity was calculated using the distance matrices generated using the phylogenetic-based method UniFrac [27] and then visualized using principal coordinates analysis (PCoA). Finally, the OTUs networks were visualized in Cytoscape v3.2.1 for depicting the similarities and differences between the different sludge fermentation systems [28]. CCA analyses were conducted by Canoco 4.5 to examine correlations between characteristic genera and the environmental and performance measurements, including $\mathrm{pH}$ and the concentrations of methane, VFAs, HAc, HPr, soluble proteins $\left(\mathrm{S}_{\mathrm{pr}}\right)$ and carbohydrates $\left(\mathrm{S}_{\mathrm{ca}}\right)$. The relative abundance of 16 characteristic bacteria was used in the CCA analysis.

\section{Analytical methods}

Sludge samples were centrifuged at 10,000 rpm $(9392 \times g)$ after anaerobic fermentation, filtered through a $0.45 \mu \mathrm{m}$ cellulose nitrate membrane filter and finally stored at 
$4{ }^{\circ} \mathrm{C}$, prior to analysis. The determination of TSS, VSS, SCOD, TCOD, carbohydrates, and proteins was performed as previously described [29]. A total of $500 \mathrm{~mL}$ Cali-5-Bond $^{\text {TM }}$ gas-sampling bags were used to collect the biogas produced. The total volume of gas was measured using a glass syringe. Gas composition was analyzed using a gas chromatograph (GC) (4890D, Agilent) equipped with a thermal conductivity detector (TCD). The cellulose, hemicellulose and lignin contents of CS were measured using a Fiber Analyzer (ANKOM, USA). The xylose, arabinose and glucose concentrations in CS hydrolysate were measured using high performance liquid chromatography (HPLC) (model e2695, Waters Co., Milford, MA). Another Agilent 7890 GC, equipped with a flame ionization detector (FID), was utilized to analyze the composition of the VFAs. VFAs production was calculated as the sum of the measured acetic (HAc), propionic ( $\mathrm{HPr}), \mathrm{n}$-butyric $(\mathrm{n}-\mathrm{HBu})$, iso-butyric (iso- $\mathrm{HBu}$ ), $\mathrm{n}$-valeric (n-HVa) and iso-valeric (iso-HVa) acids. The COD conversion factors were $1.50 \mathrm{~g} \mathrm{COD} / \mathrm{g}$ protein (assumed as $\left.\left(\mathrm{C}_{4} \mathrm{H}_{6.1} \mathrm{O}_{1.2} \mathrm{~N}\right) \mathrm{x}\right), 1.06 \mathrm{~g} \mathrm{COD} / \mathrm{g}$ carbohydrate (assumed as $\mathrm{C}_{6} \mathrm{H}_{12} \mathrm{O}_{6}$ ), $1.07 \mathrm{~g} \mathrm{COD} / \mathrm{g} \mathrm{HAc}, 1.51 \mathrm{~g} \mathrm{COD} / \mathrm{g}$ $\mathrm{HPr}, 1.82 \mathrm{~g} \mathrm{COD} / \mathrm{g} \mathrm{HBu}$, and 2.04 g COD/g HVa.

\section{Results and discussion}

Effect of feedstock proportions and CS adjustment forms on WAS digestion in the processes of hydrolysis, acidification and methanogenesis

In this study, WAS provided a nitrogen source from proteins, which were the main part of the flocs and CS offered carbon sources from carbohydrates in the form of monosaccharides $(\mathrm{H})$ and cellulose/hemicellulose polysaccharides (S). The time-course profiles of soluble organics are shown in Additional file 2: Fig. S1. A large amount of soluble carbohydrates and proteins were observed in CS and WAS co-digestion solution after pretreatments, which were maximized in the 50:50\%_HS test, i.e., $1477 \pm 22$ and $12995 \pm 247 \mathrm{mg}$ COD/L. These soluble organic compounds were rapidly consumed during the first $96 \mathrm{~h}$ of operation in conjunction with VFAs production, and then they stabilized at different levels with negligible variation until the end of the run. The stabilized soluble carbohydrates in the $65: 35 \%$ group, for instance, were estimated to be approximately 485, 527 and $484 \mathrm{mg} \mathrm{COD} / \mathrm{L}$ in the $\mathrm{H}, \mathrm{S}$ and $\mathrm{HS}$ tests, and the corresponding values for proteins were measured to be 4862, 3307 and $4198 \mathrm{mg}$ COD/L approx. The accumulation of soluble organics depends on their rates of production and consumption. Production was achieved through the hydrolysis of particulate organics, which mainly aggregated in extracellular polymeric substances (EPSs) and embedded in the microbial cells for WAS [30] and polymerized in the form of cellulose and hemicellulose polysaccharides for CS. On basis of the conversion of soluble organics in the subsequent acidification and methanogenesis processes, the highest conversion of carbohydrates and proteins were achieved in 50:50\%_H and HS tests, which were, respectively, 20 and 4.2 times higher than that in the control. With the decrease of CS feedstock proportion, there was a slight reduction in the consumed organics (890 and $5625 \mathrm{mg} \mathrm{COD} / \mathrm{L}$ in the 65:35\%_H and HS tests). Apparently, CS adjustment, no matter what the form was, improved the consumption of protein from WAS fermentation. The same phenomenon was also observed in other studies $[15,16]$.

VFAs were produced from proteins and carbohydrates biodegradation by acidogenic bacteria, and good agreement was obtained between them (Fig. 1 and Additional file 2: Fig. S1). From 96 h onward, VFAs production sharply increased in all tests and then fluctuated little with the further increase in fermentation time, especially for the co-digesting tests. In contrast, it gradually decreased with time extension in the control and 65: 35\%_H tests. Clearly, the optimal fermentation time was $96 \mathrm{~h}$ for the VFAs production. This result was in good accordance with the fact that the released soluble organics were consumed at that time (Additional file 2: Fig. S1). The maximum VFAs concentration for sludge alone was only $6320 \pm 196 \mathrm{mg}$ COD/L. Digesting sludge alone for VFAs production has been proven to be less judicious in many cases $[15,16,31,32]$. In comparison, in the case of co-digestion, no matter what the feedstock proportions and CS adjustment forms were, the addition of CS greatly upgraded the VFAs production. When 65 : $35 \%$ H, S and HS as carbon addition were employed, a marked rise in VFAs yields to $8338 \pm 276,9527 \pm 534$ and $10194 \pm 72 \mathrm{mg}$ COD/L were observed, respectively. A further rise in CS feedstock proportions contributed more significantly to VFAs production. The time-course curve showed that the sequence of VFAs production was $\mathrm{HS}>\mathrm{S}>\mathrm{H}>$ control tests. However, taking VFAs yield as the target, the conditioning of CS hydrolysate gained the higher value (564 mg VFAs-COD/g VSS, 50:50\%), which increased 20 and $24 \%$ over that of the CS_S and HS tests. A lower CS feedstock proportion (65:35\%) led to more VFAs accumulation, i.e., 583, 478 and $455 \mathrm{mg}$ VFAsCOD/g VSS in the CS_H, S and HS tests, while that was only $392 \mathrm{mg}$ COD/g VSS in the control.

VFAs, as the products of acidogenesis, are the substrates for methanogenesis and can be easily metabolized to methane. As depicted in Fig. 2, methane production was also strongly affected by the feedstock proportions and CS adjustment forms. We noted that, at the lower CS feedstock proportion (65:35\%), (cumulative) methane production was improved by CS_H or CS_S conditioning from WAS digestion. The data obtained 

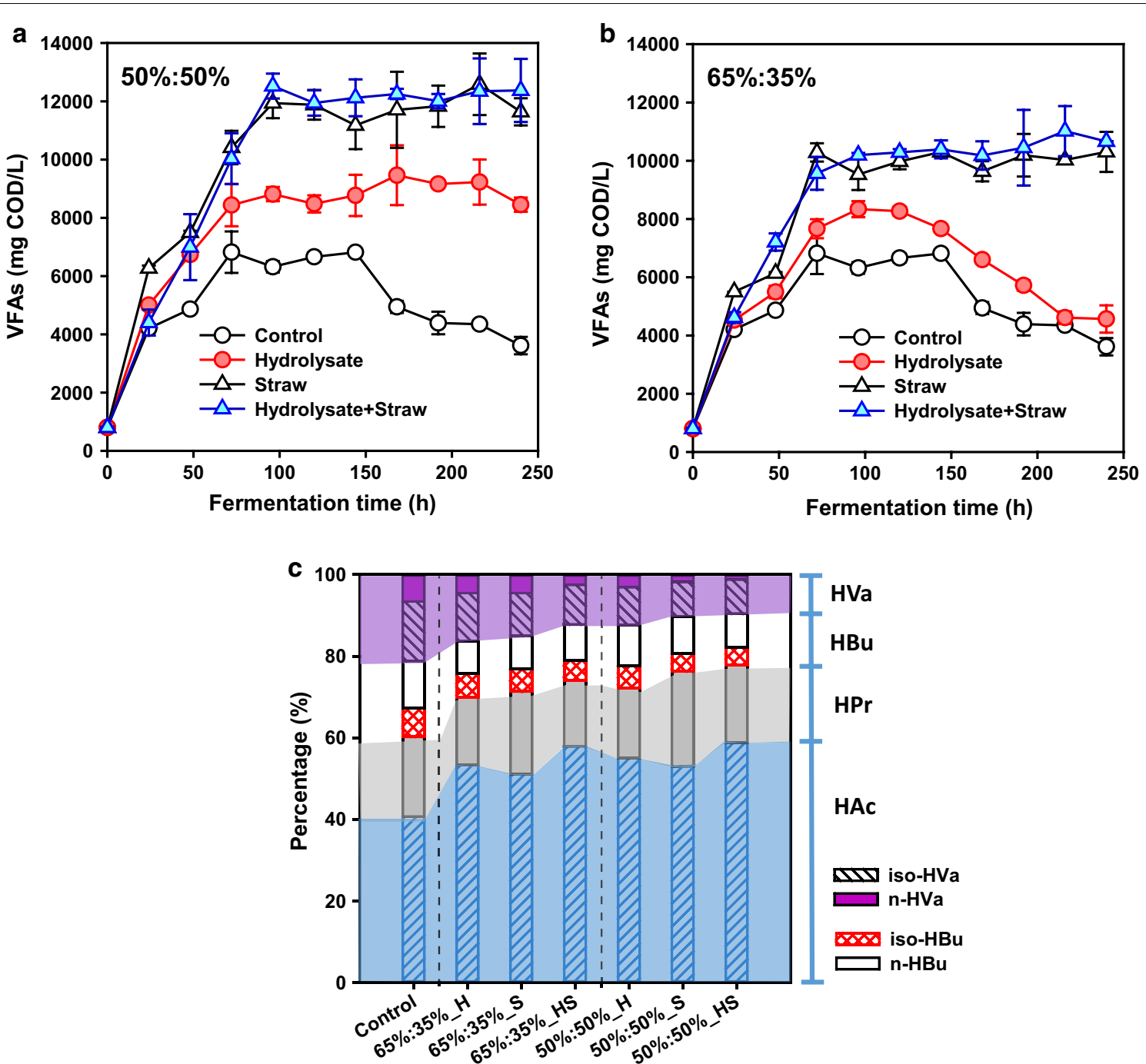

Fig. 1 Effect of CS adjustment form on VFAs production (a 50:50\%; b 65:35\%) and composition (c) from WAS co-digestion (Note: error bars represent standard deviation)

fitted the linear growth model $\left(Y_{\mathrm{CH} 4}=\right.$ constant $\left.+k t\right)$, and the corresponding production rate constants $(k)$ were calculated. The specific methane yield slightly increased from $12.5 \pm 0.9 \mathrm{~mL} / \mathrm{g}$ VSS $\left(k=0.0621 \mathrm{~h}^{-1}\right.$, $\left.R^{2}=0.9539\right)$ in the control to $16.0 \pm 0.8 \mathrm{~mL} / \mathrm{g} \mathrm{VSS}$ $\left(k=0.0563 \mathrm{~h}^{-1}, R^{2}=0.8178\right)$ and $16.1 \pm 0.2 \mathrm{~mL} / \mathrm{g}$ VSS $\left(k=0.0729 \mathrm{~h}^{-1}, R^{2}=0.8507\right)$ in the CS_S and H tests, while it was inhibited in the CS_HS test $(3.3 \pm 0.0 \mathrm{~mL} / \mathrm{g}$ VSS, $\left.k=0.0127 \mathrm{~h}^{-1}, R^{2}=0.8548\right)$ after $240 \mathrm{~h}$ of fermentation time. However, at the higher CS feedstock proportion (50:50\%), no matter what the CS adjustment form was, methanogenesis was all indeed inhibited. Wang et al. investigated the feasibility of co-digesting sludge with Quercus serrate chips, and they also reported that the addition of Quercus serrata chips inhibited the total methane production [33]. Similarly, an adverse effect of shredded grass on methane production during the codigestion with sludge was observed [34]. In this study, the $\mathrm{pH}$ reduction resulting from the high concentration of VFAs could be the reason for the low methanogenesis efficiency. It is well-known that methanogenesis is strongly $\mathrm{pH}$-dependent, and most methanogenic bacteria function in a $\mathrm{pH}$ range of 6.5-7.2 with an optimum $\mathrm{pH}$ near 7.0 [35]. In this study, we have studied the $\mathrm{pH}$ evolution in the WAS and CS co-digestion. As shown in Fig. 2c and d, the pH values of the 50:50\%_H, S and HS tests and the $65: 35 \%$ HS test at $240 \mathrm{~h}$ were all indeed beyond the optimum range. In contrast, the $\mathrm{pH}$ was in the optimum range in the $65: 35 \%$ H and control tests (7.5 and 7.4), which were consistent with the enhanced 

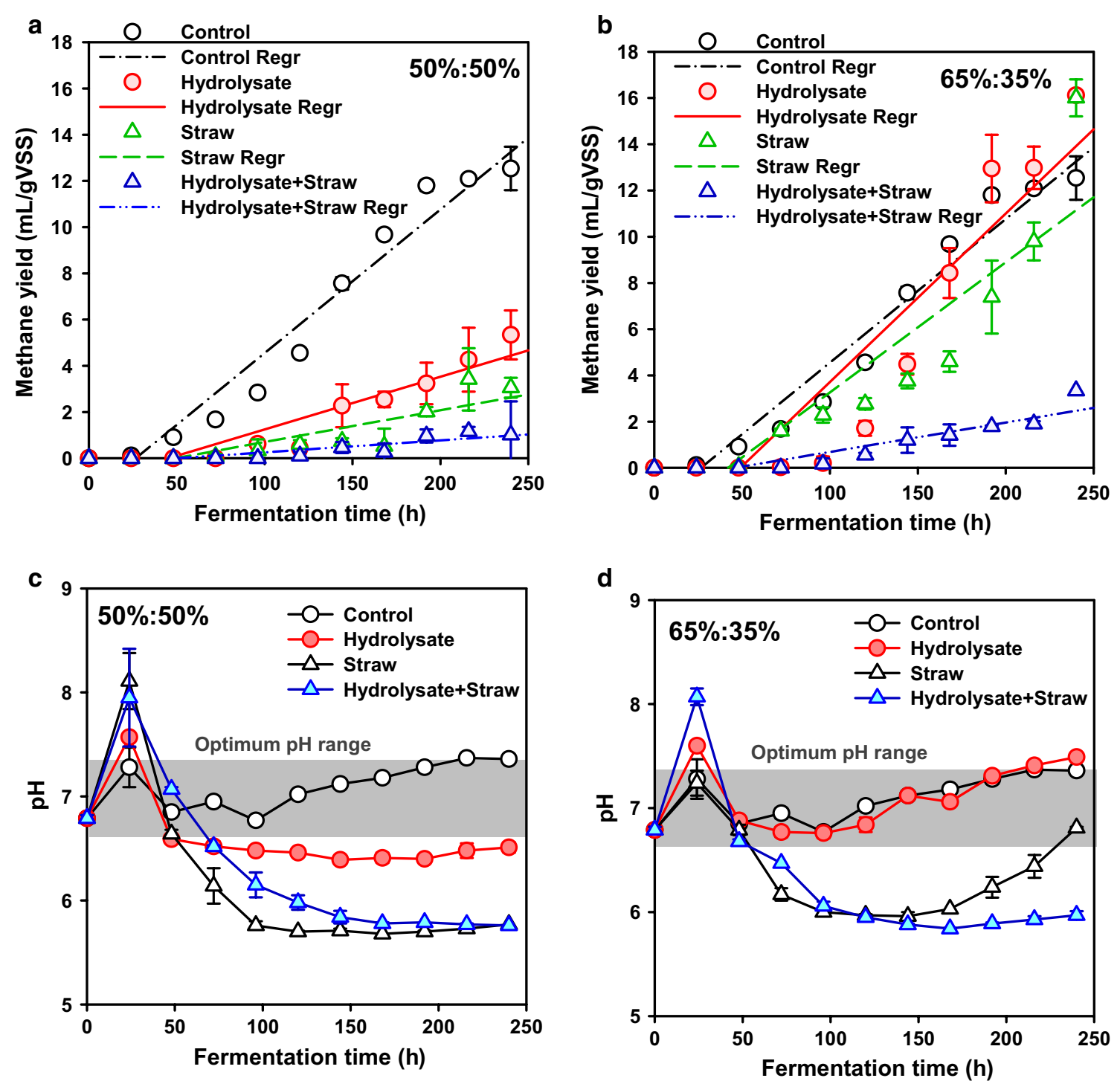

Fig. 2 Effect of CS adjustment form on methane production from WAS (a 50:50\%; b 65:35\%) and the variation of pH values during WAS and CS codigestion (a 50:50\%; b 65:35\%) (Note: error bars represent standard deviation; Panels in $\mathbf{c}$ and $\mathbf{d}$ represent the optimum pH range for methanogens)

biogas yield. Interestingly, the pH value of the 65:35\%_S test first decreased to $\sim 6.0$ from 96 to $168 \mathrm{~h}$, which led to the slight increase in methane production. With a further increase of fermentation time, the $\mathrm{pH}$ value gradually increased to $6.8(240 \mathrm{~h})$, which was conducive to the metabolism of methanogens, and the corresponding methane yield sharply increased from $4.6 \pm 0.4(168 \mathrm{~h})$ to $16.0 \pm 0.8 \mathrm{~mL} / \mathrm{g}$ VSS $(240 \mathrm{~h})$.

\section{Shift of the acidification spectrum from WAS} by conditioning with different CS forms

According to the composition analysis (Fig. 1c), the six VFAs varied with different CS proportions at $96 \mathrm{~h}$, when the VFAs had reached a plateau in most of the reactors. Among them, the top three (individual) VFAs produced were HAc (53-59\%), HPr (17-23\%) and n-HBu (8-10\%) in the 50:50\% tests. The results were somewhat in accordance with the observations of Jia et al. [15] and Feng et al. [16], who highlighted the positive role of perennial ryegrass and rice in sludge digestion. In contrast, the top produced VFAs were HAc (51-58\%), HPr (16-20\%) and iso-HVa (10-12\%) in the $65: 35 \%$ tests, which was consistent with individual WAS digestion (41, 20 and $15 \%$ for HAc, HPr and iso-HVa) (Fig. 1c). Similarly, this was also confirmed by our previous research [36] on the co-digestion of Agaricus bisporus substrates and WAS. Clearly, 
the product spectrum can be affected by the digesting feedstock proportions, especially for the distributions of $\mathrm{HVa}$ and $\mathrm{HBu}$. The reason behind this maybe that $\mathrm{HVa}$ was mainly associated with the fermentation of proteins via reductive deamination of single amino acids or by oxidation-reduction between pairs of amino acids via the Stickland reaction [37]. The yield coefficients of HVa from monosaccharides and amino acids (i.e., $f_{\mathrm{va}, \mathrm{su}}$ and $f_{\mathrm{va}, \mathrm{aa}}$ ) postulated by Anaerobic Digestion Model No.1 (ADM1) were 0 and 0.23 , respectively. As mentioned above, protein was the main constituent of WAS, which accounted for $58 \%$ of TCOD [19]. When digesting sludge alone, of course, the harvest was considerably more abundant in HVa (21\%) than that in the conditioning tests. With the increase of the CS proportion to $35 \%$ and further to $50 \%$, HVa was decreased to 12 and $9 \%$ in the HS groups. HBu was also abundant for digesting sludge alone (19\%). With the increase of the CS proportion to $35 \%$ (50\%), HBu correspondingly decreased to $14 \%(12 \%)$ in the HS groups. It was reported that $\mathrm{HVa}$ and $\mathrm{HBu}$ can be converted into HAc and HPr via the $B$-oxidation pathway by acetogenic bacteria in the syntrophic acetogenesis process, and the specific thermodynamic equation of $\mathrm{HBu}$ and $\mathrm{HVa}$ degradation was shown as the following [37]:

$$
\begin{aligned}
& \mathrm{HBu}+2 \mathrm{H}_{2} \mathrm{O} \rightarrow 2 \mathrm{HAc}+2 \mathrm{H}_{2} \\
& \mathrm{HVa}+2 \mathrm{H}_{2} \mathrm{O} \rightarrow \mathrm{HPr}+\mathrm{HAc}+2 \mathrm{H}_{2}
\end{aligned}
$$

From an overall perspective, the conditioning of WAS digestion by external CS addition was an efficient approach for the transformation of high-molecular-weight VFAs (e.g., $\mathrm{HVa}$ and $\mathrm{HBu}$ ) to lowmolecular-weight VFAs (HAc and HPr).

\section{Overall analysis of Illumina sequence data}

In total, four $16 \mathrm{~S}$ rRNA gene libraries of the $65: 35 \%$ codigestion and control tests at $240 \mathrm{~h}$ were constructed from MiSeq sequencing, in total, with 101,567 high-quality reads (average length of $450 \mathrm{bp}$ ), and they were subsequently clustered into 11,733 OTUs at a $3 \%$ distance (Additional file 3: Table S2). Rarefaction curves for all libraries displayed shapes indicative of effective sampling of community diversity (Additional file 4: Fig. S2). The microbial diversities of the evolving communities were assessed based on $\alpha$-diversity. The Shannon diversity index provided the species evenness, indicating that the control had the highest diversity (Shannon 6.29) among the four communities. Based on the Chao1 indices, in which the richness was indicated, the control also had relatively higher diversity (7663). A reduction in bacterial diversity occurred in the co-digesting tests, caused by the directional selection of bacteria, which resulted in the loss of biodiversity (Additional file 3: Table S2).
The similarity of the microbiome was calculated and examined by $\beta$-diversity. Differences in the bacterial community composition among the samples were assessed by PCoA, generated from unweighted UniFrac (Additional file 5: Fig. S3A). Principal components 1 and 2 explained 25.3 and $24.3 \%$ of the bacterial community composition variations, respectively. It was clear that the four samples were totally separated from each other, which was further proven by the results of hierarchical cluster analysis (HCA) (Additional file 5: Fig. S3B). That is, conditioning with CS, in different adjustment forms, substantially changed the bacterial community structure, despite the fact that the same initial source of the WAS microbial consortia was shared. To elucidate the interactions among all of the OTUs and analyze the shared and most abundant OTUs in the four WAS samples, the OTU network was constructed (Fig. 3a). Collectively, only 457 phylum-level OTUs were shared. The majority of the shared OTUs were Proteobacteria (33\%), Firmicutes (12\%) and Bacteroidetes (9\%) (Fig. 3b).

\section{Microbial diversity and distribution analysis}

Phylogenetic analysis of the $16 \mathrm{~S}$ rRNA gene sequences was performed at the phylum, class and genus levels to further investigate the diversity of the microbial community. Clear changes were observed in microbial community structures during WAS co-digestion with CS in different adjustment forms (Fig. 3c, d). The phyla Firmicutes, Bacteroidetes, Chloroflexi and Proteobacteria, which were recognized as common anaerobic fermentation phyla, were dominant in the four communities. Firmicutes were primarily dominant in the co-digesting tests, with 36, 28 and $35 \%$ in $\mathrm{H}, \mathrm{S}$ and HS, compared with $9 \%$ in the control. As reported, Firmicutes played a critical role in the anaerobic hydrolysis and acidification process [38]. Almost the same trend was observed for Bacteroidetes. Conversely, Chloroflexi and Proteobacteria decreased in all co-digesting samples. Such major difference of distributions of phyla between the sludge digestion alone and the co-digestion tests should be responsible for the distinct conditioning effects of CS addition, with different forms, on WAS digestion.

Pyrosequencing detected 67 bacterial classes in all four communities. The majority of sequences belonged to 12 classes, among which Clostridia (phylum Firmicutes) and Bacteroidia (phylum Bacteroidetes) were the dominant ones. The sum accounted for $45-76 \%$ of the total bacterial sequences for the co-digesting tests, while that was only $11 \%$ in the control (Fig. 3d). Clostirida was reported to consist of abundant anaerobic species and capable of decomposing solid wastes and producing organic acids by cellulolytic enzymes [39]. Bacteroidia was one of the few types of bacteria resistant to the extreme $\mathrm{pH}$ 

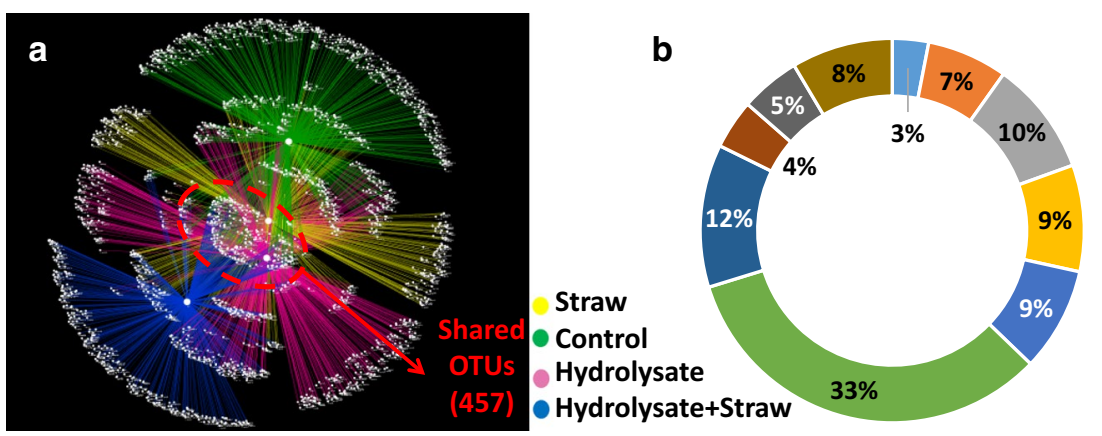

- Acidobacteria

Actinobacteria

Bacteroidetes

Chloroflexi

- Planctomycetes

- Proteobacteria

- Firmicutes

- Saccharibacteria

- unclassified

others

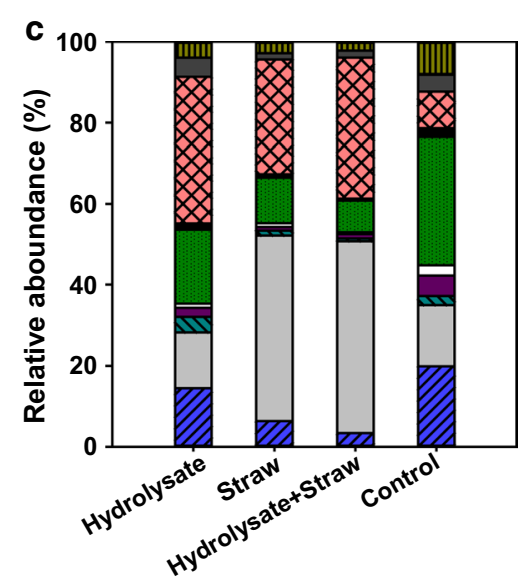

d
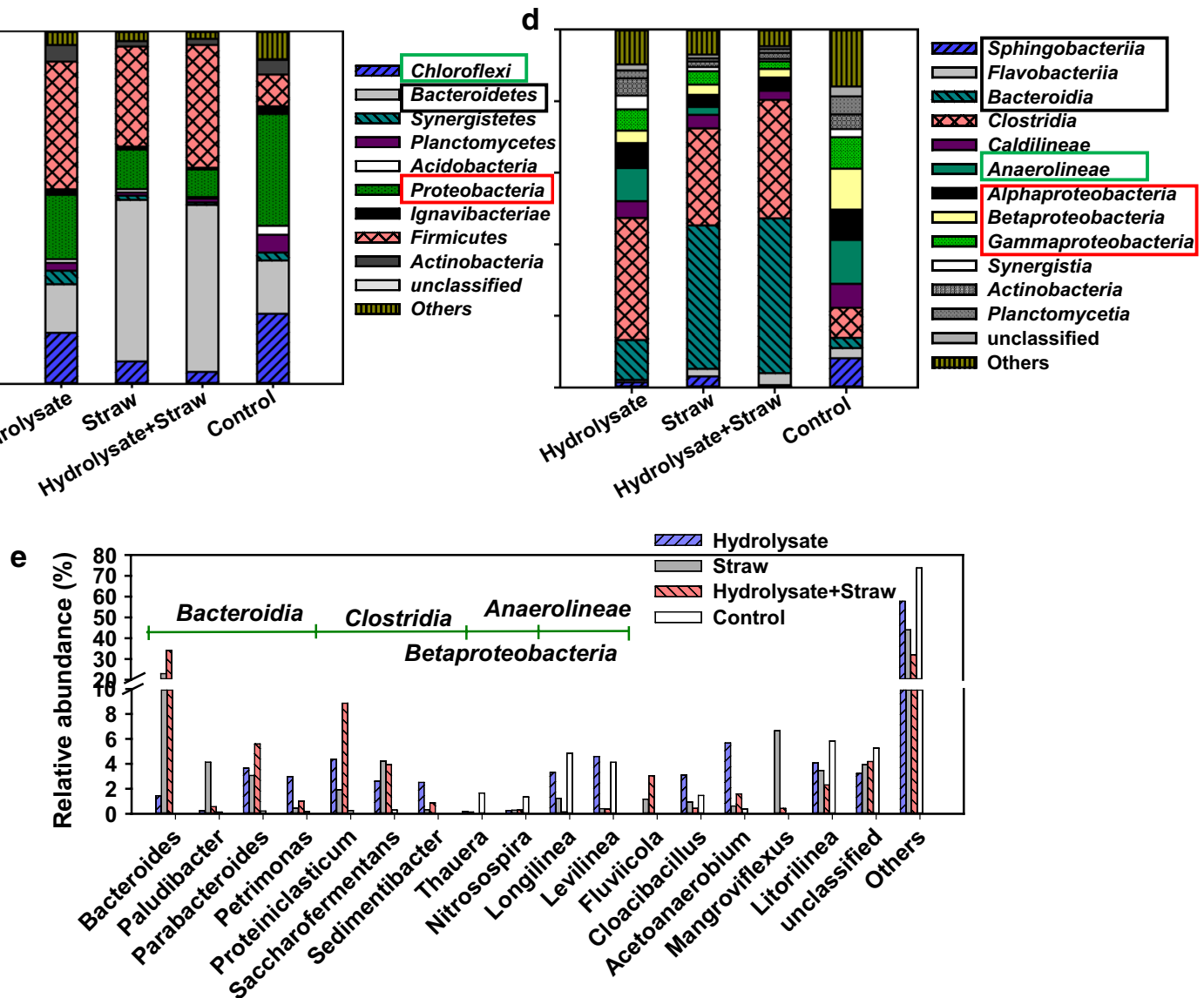

Fig. 3 OTU networks of the bacterial communities (a). Overlaps of the bacterial communities based on OTU (3\% distance). The shared OTUs were analyzed at phylum level (b). Relative abundance was defined as the number of sequences per sample. Taxonomic classification of pyrosequences from the four WAS bacterial communities at the phylum (c), class (d) and genus (e) levels

conditions, and it was reported to play a critical role in sludge reduction [40].

Further investigation on the genus level provided more detailed information about microbial communities (Fig. 3e). Bacteroides (belonging to the class Bacteroidia) took up the largest proportion of co-digesting tests, especially in S (23\%) and HS (34\%), and it was identified as one of the most dominant heterotrophic organisms in anaerobic wastewater treatment sludge and was capable of converting proteins and carbohydrates to $\mathrm{HPr}$ and HAc as its primary products in anaerobic sludge fermentation [41]. As one of class Bacteroidia, Paludibacter reached the highest abundance in S (4\%), which was commonly considered to be a strictly anaerobic, $\mathrm{HPr}-$ producing bacterium [42]. Mangroviflexu (belonging to class Marinilabiaceae), which was also mainly detected in S (7\%), was an obligately anaerobic mesophilic microorganisms and be able to ferment various substrates with the production of HPr, HAc, and succinate [43]. This was a good explanation for the higher produced HPr in 
CS_S conditioning test than that in $\mathrm{H}$ and HS (Figs. 1c, 3b). Moreover, among these class Bacteroidia microorganisms, Parabacteroide and Petrimonas, which were abundant in HS (6\%) and $\mathrm{H}(3 \%)$, were also reported to have the ability to degrade complex organic matter to form acid [26, 44]. Three genera of Clostridia (Proteiniclasticum, Saccharofermentans and Sedimentibacter) were identified. It is worth noting that a high protein or polysaccharide content would lead to the dominance of Proteiniclasticum (highest in HS (9\%)), which is able to produce VFAs as end products from fermentation [45]. For Saccharofermentans, the main end products of fermentation from glucose were HAc, lactate and fumarate [46], which peaked at $\sim 4 \%$ in S. Sedimentibacter, which was mainly detected in $\mathrm{H}(3 \%)$ and only enriched at around $\mathrm{pH}$ 8.0, was known to ferment proteins through Stickland-type reactions to produce VFAs [47]. As stated in Fig. 2d, the $\mathrm{pH}$ was approximately 7.5 in the $\mathrm{H}$ test on day 10, which was beneficial for Sedimentibacter metabolism. The other dominant genera in $\mathrm{H}$ were Cloacibacillus (class Synergistia, 3\%) and Acetoanaerobium (class Bacilli, 6\%), which were specialized in amino-acid- biodegradation [48] and $\mathrm{HAc}$ production (from $\mathrm{H}_{2}$ and $\mathrm{CO}_{2}$ ) [49]. The dominant genera in the control included Thauera (2\%), Nitrosospira (1\%), Longilinea (5\%) and Levilinea (4\%), which were all common microbial consortia during the wastewater treatment.

\section{Correlation between environmental variables and microbial populations}

To better understand the roles and importance of individual microbial groups in different CS and WAS codigestion processes, plausible relationship between characteristic genera and the environmental and performance measurements, including $\mathrm{pH}$, methane, VFAs, $\mathrm{HAc}, \mathrm{HPr}, \mathrm{S}_{\mathrm{pr}}$ and $\mathrm{S}_{\mathrm{ca}}$ concentrations, were evaluated using CCA (Fig. 4). Based on the assumption that the WAS digestion process is most likely driven by the predominant bacteria, we performed CCA analysis using 16 characteristic bacteria. This result can explain why different adjustment forms of CS could influence the WAS hydrolysis, acidification and methanogenesis efficiencies. The contents of methane and $\mathrm{pH}$ were proven to be positively correlated with the first canonical axis (explaining $63.4 \%$ of the variance of the genera distribution), and the contents of $\mathrm{S}_{\mathrm{pr}}, \mathrm{S}_{\mathrm{ca}}$, VFAs, HAc and HPr showed negative interrelations. For axis 2 (explaining $23.9 \%$ variance), only the HPr content showed good positive correlation. The detailed information is shown in Additional file 6: Table S3. The length of an arrow-line indicates the strength of the relationship between the environmental variable and the microbial community. As indicated, VFAs and HAc were strongly linked to the

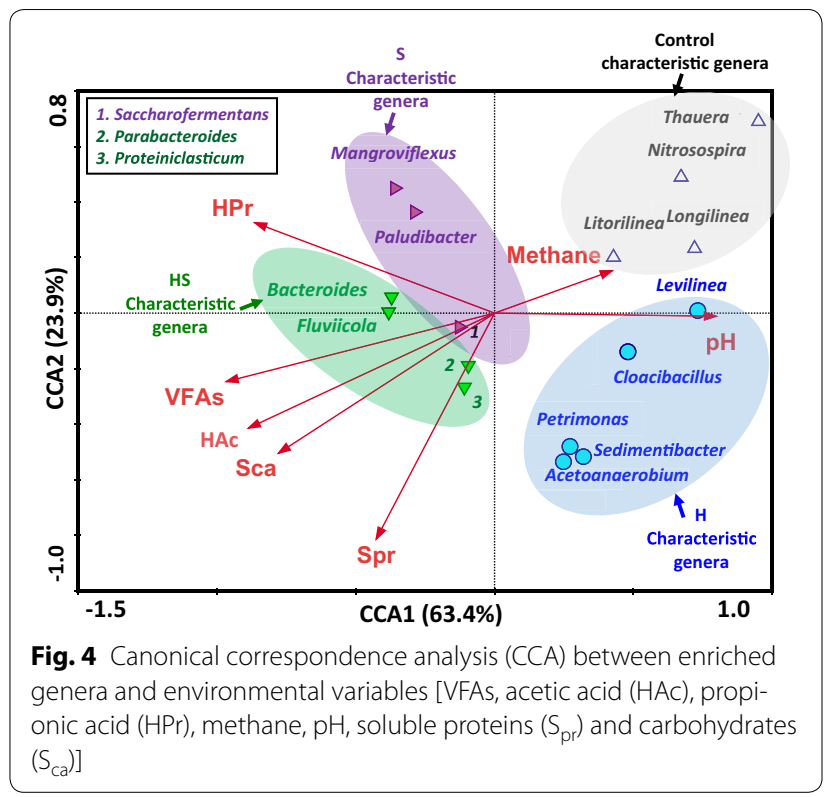

microbial community according to the length of the vector, followed by HPr and Sca. Moreover, the intersection angle between $\mathrm{S}_{\mathrm{pr}}$ and $\mathrm{HAc} / \mathrm{HPr}$ was bigger than that of $S_{\mathrm{ca}}$, indicating that the $S_{\mathrm{ca}}$ was more related to HAc and HPr production than $S_{\mathrm{pr}}$. This could be verified by the yield coefficients of HAc and HPr from monosaccharides and amino acids (i.e., $f_{\mathrm{ac}, \mathrm{su}}, f_{\mathrm{ac}, \mathrm{aa}}, f_{\mathrm{pr}, \mathrm{su}}$ and $f_{\mathrm{pr}, \mathrm{aa}}$ ), which were 0.41 vs 0.40 and 0.27 vs 0.05 , respectively [37]. The changes of $\mathrm{S}_{\mathrm{ca}}$ and $\mathrm{S}_{\mathrm{pr}}$ concentrations were closed to VFA production (including HAc and $\mathrm{HPr}$ ), indicating that the efficiency of WAS hydrolysis plays an important role in the subsequent acidification process. As stated, it was also found that $\mathrm{pH}$ was closely related to methane production, which was consistent with the above discussions ("Effect of feedstock proportions and CS adjustment forms on WAS digestion in the processes of hydrolysis, acidification and methanogenesis" section). In view of the CCA result (Fig. 4), we found that $\mathrm{pH}$ and methane production had very high positive correlation with some bacterial genera, including Thauera, Nitrosospira, Longilinea, Litorilinea, Levilinea and Cloacibacillus, which were abundant in the control and $\mathrm{H}$ tests. Mangroviflexus was highly correlated with HPr production, followed by Paludibacter, which was the characteristic genus in S. Bacteroides was comparatively correlated with HAc and VFAs production, followed by Fluviicola (the characteristic genus in HS). Instead, the characteristic genera in $\mathrm{H}$ were Acetoanaerobium, Petrimonas and Sedimentibacter, which were closely related to $S_{\mathrm{pr}}$. Note that these characteristic genera could be enriched by the feedstocks with certain contents of cellulose, hemicellulose (mainly in S) or their saccharification hydrolysates (mainly in $\mathrm{H}$ ). In this sense, the CCA results suggested that adjustment 
forms of external carbon sources may play an important role in structuring the innate microbial community in WAS and the relationship between community structure and the measured variables may reveal the whole CS and WAS co-digestion process.

\section{Significances and potential implementation}

This study demonstrated for the first time, the effect of $\mathrm{CS}$ conditioning with different adjustment forms $(\mathrm{H}, \mathrm{S}$ and HS) on enhancing the WAS digestion efficiency by process assessment associated with microbial community response analysis. Experimental results showed that the highest VFAs yield was achieved by $\mathrm{H}$ adjustment ( $\sim 574 \mathrm{mg}$ COD/g VSS), followed by S ( $478 \mathrm{mg} \mathrm{COD/g}$ VSS) and then by HS ( 454 $\mathrm{mg}$ COD/g VSS), no matter what the feedstock proportion was. In contrast, it was only $392 \mathrm{mg}$ COD/g VSS for the control. Clearly, the conditioning of CS greatly upgraded the WAS acidification performance. A marked rise in VFAs yield was observed when CS hydrolysate was employed. A comparison of VFAs yield from WAS digestion by co-digesting carbonrich substrates is given in Table 1 . The yield obtained in 65:35\%_H was considerably larger than what has been previously reported $[15,16,31,32,36,50]$.

VFAs composition is considered to be crucial when the WAS hydrolysate is used as an external carbon source. Among the six VFA, HAc was regarded as the favorite substrate for many bioprocesses, such as nutrient removal [51] and co-polymer production [52]. HAc was strongly dependent on adjustment form. HS conditioning groups yielded more HAc $(\sim 58 \%)$, followed by $\mathrm{H}(\sim 54 \%)$ and S $(\sim 52 \%)$ groups. Some researchers also explored almost the same approach to produce HAc by co-fermentation with other carbon-rich substrates. Morgan-Sagastume et al. reported that the HAc ratio to other acids was higher when fermenting the mixture of primary sludge and WAS [53]. Meanwhile, HPr was also considered to be an important component for biological phosphorus removal [54]. Pijuan et al. showed that the biological removal of phosphorus was enhanced when using HPr as the sole carbon source [55]. In this study, we found that HPr was also dependent on adjustment form. That is, lower HPr was produced in the $\mathrm{H}$ and HS groups ( 17 and $\sim 18 \%$ ), while higher HPr was produced in the $\mathrm{S}$ groups $(22 \%)$. The sum of the concentrations of HAc and HPr was maximized in the 50:50\%_HS test (78\%, $9751 \mathrm{mg} \mathrm{COD} / \mathrm{L})$, versus 74\% (7552 $\mathrm{mg} \mathrm{COD} / \mathrm{L})$ and $60 \%$ (3803 $\mathrm{mg} \mathrm{COD} / \mathrm{L})$ in the $65: 35 \%$ HS and control tests.

An ecological estimation was conducted for the entire process based on the exemplary 100,000 metric tones (mts) capacity WWTPs and the corn produced in the planting area of one acre. The amount of WAS was calculated according to Feng et al. and the capacity was 43.8 mts/d (745 kg/d (in VSS)) [56]. In 2015, Shanxi Province in China generated 9.4 million tones of corn in the planting area of 1.7 million hectares [20]. Since straw is not a statistical index but rather a complex unit, we estimated the amount of straw by the ratio of residue to grain, which was reported to be approximately 1.25 for corn [57]. Then, we finally obtained the $2378 \mathrm{~kg} / \mathrm{acre}$ (in VSS) capacity for CS. Currently, conventional WAS and CS disposal routes were mainly land application, incineration, landfill, silage or even improper dumping (Fig. 5a). Figure 5b demonstrates the new carbon source recovery concept, as applied in a WWTP, by WAS digestion conditioning with CS in different adjustment forms. This finding showed that it will be very considerable to harvest VFAs as a carbon source, especially for the $65: 35 \%$ WAS and CS co-digesting groups. By calculation, the VFAs yield (in COD) will be 2165,2729 and $2597 \mathrm{~kg}$ per acre CS with the adjustment forms of $\mathrm{H}, \mathrm{S}$ and HS. More importantly, the amount of WAS treated in this case will be equivalent to that produced in a 500,000 mts capacity WWTPs per day. That will be only $1451 \mathrm{~kg}$ VFAs (as COD) for WAS digesting alone. Moreover, as far as the entire CS (one acre) was

Table 1 Comparison of VFAs yield from WAS fermentation by co-digesting carbon-rich substrates

\begin{tabular}{|c|c|c|c|c|}
\hline Sludge & $\begin{array}{l}\text { Carbon-rich substrates (adjust- } \\
\text { ment forms) }\end{array}$ & Feedstock proportions & VFAs yield & References \\
\hline Adjusting pH (8)-treated WAS & $\begin{array}{l}\text { Thermal-treated rice (TTR) } \\
\text { (Solid) }\end{array}$ & $50: 50 \%\left(\right.$ VSS $\left._{\text {WAS }}: V_{S S} S_{\text {TTR }}\right)$ & 520 mg COD/g VSS & {$[16]$} \\
\hline WAS & Perennial ryegrass (Solid) & $20: 1(\mathrm{C} / \mathrm{N})$ & 369 mg COD/g TS & {$[15]$} \\
\hline Mixed sludge (MS) & Lime-treated bagasse (LTB) (Solid) & $\begin{array}{l}30: 70 \%, 40: 60 \% \text { and } 60: 40 \% \\
\left(g_{\text {MS }}: g_{\text {LTB }}\right)\end{array}$ & 360 mg carboxylic acid/g VS & {$[31]$} \\
\hline Alkaline- thermal treated WAS & $\begin{array}{l}\text { Agaricus bisporus substrates (ABS) } \\
\text { (Solid) }\end{array}$ & $45: 55 \%\left(V_{S S} S_{\text {AS }}: V_{S S} S_{A B S}\right)$ & $514 \mathrm{mg}$ COD/g VSS $\mathrm{WAS}+\mathrm{ABS}$ & {$[36]$} \\
\hline WAS & $\begin{array}{l}\text { Sugar beet pulp lixiviation (SBPL) } \\
\text { (Solid) }\end{array}$ & $75: 25 \%\left(v_{S S}: V_{S B P L}\right)$ & 350 mg COD/g VSS & {$[32]$} \\
\hline Dewatered WAS & Food waste (FW) (Solid) & $12: 88 \%\left(V_{S S} S_{W A S}: V_{F W}\right)$ & 393 mg/g VSS & {$[50]$} \\
\hline Ultrasonic treated WAS & Alkaline treated CS hydrolysate & $65: 35 \%\left(\right.$ VSS $\left._{\text {WAS }}: V_{C S}\right)$ & $583 \mathrm{mg}$ COD/g VSS & This study \\
\hline
\end{tabular}




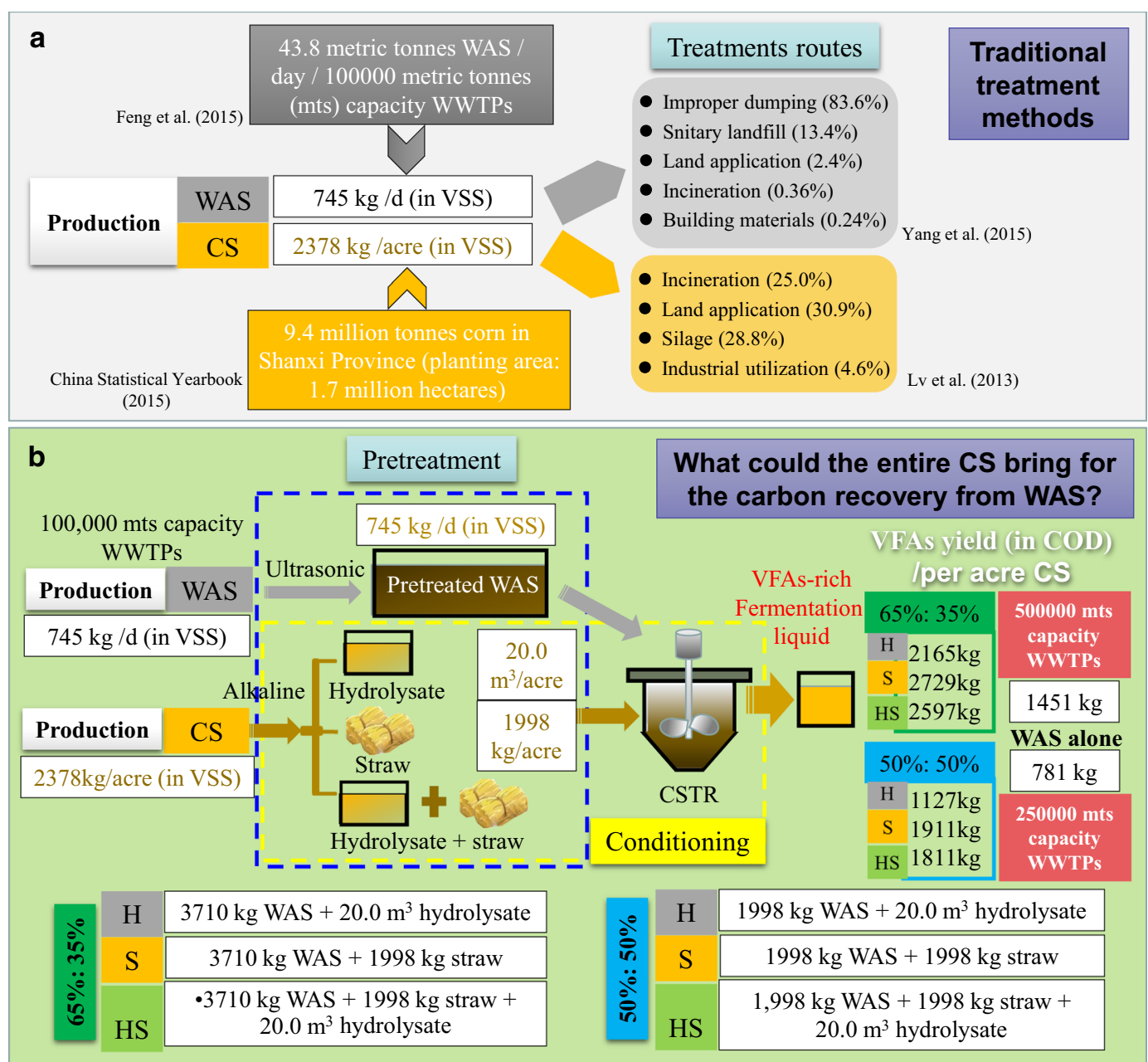

Fig. 5 Schematic diagram of traditional treatment methods (a) and an enhanced concept applied in a WWTP with the WAS digestion conditioning with different CS adjustment forms (b)

concerned, that is, including not only pretreated CS but also hydrolysate, the capacity of WAS treatment would achieve that is produced in a one million mts capacity WWTPs per day, where $4894 \mathrm{~kg}$ VFAs could be harvested. It is well-known that the removal of $1 \mathrm{mg}$ nitrogen and $1 \mathrm{mg}$ phosphorus consumes respectively $6-8 \mathrm{mg}$ [58] and 7-10 mg COD [59]. In this case, specific removal amounts of nutrients, consuming $4894 \mathrm{~kg}$ VFAs, could be calculated to be at least $610 \mathrm{~kg}$ nitrogen or $490 \mathrm{~kg}$ phosphorus. Since it is expected that the problem of WAS disposal and biological treatment of nutrients will become more acute in the next decades for China, the implementation of this carbon recovery process from WAS digestion, conditioning by CS external addition, will be of increasing interest. Certainly, the practical implementation should further assess the potential challenges in WWTPs associated with management. In addition, the whole processes must be systematically developed along with life cycle, economic and ecological assessments for ensuring sustainability.

\section{Conclusions}

CS conditioning, with three adjustment forms (S, H and $\mathrm{HS}$ ), exerted a positive influence on VFAs production and composition during anaerobic co-digestion with WAS. A comprehensive study to shed light on the underlying mechanism was undertaken for the first time by means of process assessment associated with microbial community response analysis. CS_H conditioning gained a higher VFAs yield. Pyrosequencing revealed that the abundance of anaerobic functional microorganisms was significantly advantageous to the VFAs composition shift in three codigesting systems. Adjustment forms of CS played an important role in structuring the innate microbial community in WAS. CCA analysis showed that the relationship 
between microbial community structure and the measured variables revealed the whole CS and WAS co-digestion process. Further investigation by ecological estimation revealed that the findings obtained in this study may have crucial implications for the operation of WWTPs.

\section{Additional files}

Additional file 1: Table S1. The main characteristics of the substrates.

Additional file 2: Fig. S1. Time-course profiles of soluble proteins (A: 5\%:50\%; B: 65\%:35\%) and carbohydrates (C: 50\%:50\%; D: 65\%:35\%) during entire digestion time (Note: error bars represent standard deviation).

Additional file 3: Table S2. Alpha diversity of the four samples.

Additional file 4: Fig. S2. Rarefaction curves of bacterial communities from chemical-treated WASs based on pyrosequencing of 16S rRNA gene.

Additional file 5: Fig. S3. Principal coordinate analysis (PCOA) based on the unweighted Unifrac analyses (A). PC1 and PC2 axes represent 25.33\% and $24.34 \%$ of the variance within the microbial community. Hierarchical cluster analysis of classified OTUs from the four WAS bacterial communities (B). The OTUs of $y$-axis were ordered by phylum (3\% distance). Sample communities were clustered based on complete linkage method. The color intensity of scale indicates relative abundance of each OTU read.

Additional file 6: Table S3. The eigenvalues of first two canonical axes and their relationships with each environmental factor.

\section{Abbreviations}

BNR: biological nutrients removal; CCA: canonical correspondence analysis; C/N: carbon-to-nitrogen; CS: corn stover; ECS: extra carbon sources; EPSs: extracellular polymeric substances; FID: flame ionization detector; GC: gas chromatography; H: hydrolysate; HAc: acetic acids; HPLC: high performance liquid chromatography; HPr: propionic acids; HS: hydrolysate + straw; iso-HBu: iso-butyric acids; iso-HVa: iso-valeric acids; mts: metric tones; n-HBu: n-butyric acids; n-HVa: n-valeric acids; OUT: operational taxonomic unit; PCR: polymerase chain reaction; S: pretreated straw; SCOD: soluble chemical oxygen demand; TCD: thermal conductivity detector; TCOD: total chemical oxygen demand; TSS: total suspended solids; VFAs: volatile fatty acids; VSS: volatile suspended solids; WAS: waste activated sludge; WWTPs: wastewater treatment plants.

\section{Authors' contributions}

$A Z$ and $J Z$ designed and carried out the experiments, performed the data analysis, and drafted the manuscript. KW and ZL carried out the pretreatment method, participated in the setup operation and maintenance of the bioreactors. WL and GW participated in data analysis for pyrosequencing results and revised the manuscript. AW and XY conceived the idea of the study, put forward the hypothesis and made the final revisions of figures, and gave the final approval of publication. All authors read and approved the final manuscript.

\section{Author details}

${ }^{1}$ College of Environmental Science and Engineering, Taiyuan University of Technology, 030024 Taiyuan, China. ${ }^{2}$ State Key Laboratory Breeding Base of Coal Science and Technology Co-founded by Shanxi Province and the Ministry of Science and Technology, Taiyuan University of Technology, Taiyuan, China. ${ }^{3}$ College of Architecture and Civil Engineering, Taiyuan University of Technology, Taiyuan, China. ${ }^{4}$ Research Center for Eco-Environmental Sciences, Chinese Academy of Sciences, Beijing, China. ${ }^{5}$ State Key Laboratory of Urban Water Resource and Environment, Harbin Institute of Technology (SKLUWRE, HIT), Harbin, China.

\section{Acknowledgements}

The authors thank Bin Liang for technical assistance and valuable discussion. They would like to thank the reviewers for positive criticism to improve the quality of the manuscript.

\section{Competing interests}

The authors declare that they have no competing interests.

\section{Availability of supporting data}

We provide support if necessary data for publication of the article.

\section{Consent for publication}

All the authors consented on the publication of this work.

\section{Funding}

This research was supported by National Natural Science Foundation of China (NSFC, No. 51378330, 51408396 and 51608345), by State Key Laboratory Breeding Base of Coal Science and Technology Co-founded by Shanxi Province and the Ministry of Science and Technology, Taiyuan University of Technology (No: MKX201504), by China Postdoctoral Science Foundation (No. 2015M570241 and 2016M591416), by the Key Research and Development (R\&D) Project of Shanxi Province (No. 201603D321012) and the International Science and Technology Cooperation Project of Shanxi Province (2014081007-1)

Received: 29 July 2016 Accepted: 1 November 2016

Published online: 09 November 2016

\section{References}

1. Yang $G$, Zhang G, Wang H. Current state of sludge production, management, treatment and disposal in China. Water Res. 2015;78:60-73.

2. Wei Y, Van Houten RT, Borger AR, Eikelboom DH, Fan Y. Minimization of excess sludge production for biological wastewater treatment. Water Res. 2003:37:4453-67.

3. He Z-W, Liu W-Z, Wang L, Tang C-C, Guo Z-C, Yang C-X, Wang A-J. Clarification of phosphorus fractions and phosphorus release enhancement mechanism related to $\mathrm{pH}$ during waste activated sludge treatment. Bioresour Technol. 2016;222:217-25.

4. Liu W, Cai W, Guo Z, Wang L, Yang C, Varrone C, Wang A. Microbial electrolysis contribution to anaerobic digestion of waste activated sludge, leading to accelerated methane production. Renew Energ. 2016;91:334-9.

5. He Z, Zhou A, Yang C, Guo Z, Wang A, Liu W, Nan J. Toward bioenergy recovery from waste activated sludge: improving bio-hydrogen production and sludge reduction by pretreatment coupled with anaerobic digestion-microbial electrolysis cells. RSC Adv. 2015;5:48413-20.

6. Yuan H, Chen Y, Zhang H, Jiang S, Zhou Q, Gu G. Improved bioproduction of short-chain fatty acids (SCFAs) from excess sludge under alkaline conditions. Environ Sci Technol. 2006;40:2025-9.

7. Zhou A, Yang C, Guo Z, Hou Y, Liu W, Wang A. Volatile fatty acids accumulation and rhamnolipid generation in situ from waste activated sludge fermentation stimulated by external rhamnolipid addition. Biochem Eng J. 2013;77:240-5.

8. Appels L, Baeyens J, Degrève J, Dewil R. Principles and potential of the anaerobic digestion of waste-activated sludge. Prog Energ Combust. 2008:34:755-81.

9. Ji Z, Chen Y. Using sludge fermentation liquid to improve wastewater short-cut nitrification-denitrification and denitrifying phosphorus removal via nitrite. Environ Sci Technol. 2010;44:8957-63.

10. Lehtomäki A, Huttunen S, Rintala J. Laboratory investigations on co-digestion of energy crops and crop residues with cow manure for methane production: effect of crop to manure ratio. Resour Conserv Recycl. 2007;51:591-609.

11. Chen Y, Jiang S, Yuan H, Zhou Q, Gu G. Hydrolysis and acidification of waste activated sludge at different pHs. Water Res. 2007;41:683-9.

12. Yuan $Q$, Sparling $R$, Oleszkiewicz JA. VFA generation from waste activated sludge: effect of temperature and mixing. Chemosphere. 2011;82:603-7.

13. Carlsson M, Lagerkvist A, Morgan-Sagastume F. The effects of substrate pre-treatment on anaerobic digestion systems: a review. Waste Manag. 2012;32:1634-50

14. Kayhanian M, Tchobanoglous $\mathrm{G}$. Computation of $\mathrm{C}: \mathrm{N}$ ratios for various organic fractions. Biocycle. 1992;33:58-60.

15. Jia S, Dai X, Zhang D, Dai L, Wang R, Zhao J. Improved bioproduction of short-chain fatty acids from waste activated sludge by perennial ryegrass addition. Water Res. 2013:47:4576-84. 
16. Feng $L, C$ Chen $Y$, Zheng $X$. Enhancement of waste activated sludge protein conversion and volatile fatty acids accumulation during waste activated sludge anaerobic fermentation by carbohydrate substrate addition: the effect of $\mathrm{pH}$. Environ Sci Technol. 2009;43:4373-80.

17. Zhen G, Lu X, Kobayashi T, Li Y-Y, Xu K, Zhao Y. Mesophilic anaerobic co-digestion of waste activated sludge and Egeria densa: performance assessment and kinetic analysis. Appl Energ. 2015;148:78-86.

18. Guo Z, Zhou A, Yang C, Liang B, Sangeetha T, He Z, Wang L, Cai W, Wang A, Liu W. Enhanced short chain fatty acids production from waste activated sludge conditioning with typical agricultural residues: carbon source composition regulates community functions. Biotechnol Biofuel. 2015;8:192.

19. Zhou A, Guo Z, Yang C, Kong F, Liu W, Wang A. Volatile fatty acids productivity by anaerobic co-digesting waste activated sludge and corn straw: effect of feedstock proportion. J Biotechnol. 2013;168:234-9.

20. ChinaNBoSo. China Statistical Yearbook 2015. Beijing: China Statistics Press; 2015.

21. Zhao L, Cao G-L, Wang A-J, Ren H-Y, Xu C-J, Ren N-Q. Enzymatic saccharification of cornstalk by onsite cellulases produced by Trichoderma viride for enhanced biohydrogen production. GCB Bioenerg. 2013;5:591-8

22. Liu W, He Z, Yang C, Zhou A, Guo Z, Liang B, Varrone C, Wang AJ. Microbial network for waste activated sludge cascade utilization in an integrated system of microbial electrolysis and anaerobic fermentation. Biotechnol Biofuels. 2016;9(1):1

23. Zheng X, Su Y, Li X, Xiao N, Wang D, Chen Y. Pyrosequencing reveals the key microorganisms involved in sludge alkaline fermentation for efficient short-chain fatty acids production. Environ Sci Technol. 2013:47:4262-8.

24. Liu W, Wang A, Cheng S, Logan BE, Yu H, Deng Y, Nostrand JD, Wu L, He Z, Zhou J. Geochip-based functional gene analysis of anodophilic communities in microbial electrolysis cells under different operational modes. Environ Sci Technol. 2010;44(19):7729-35.

25. Zhou J, Liu W, Deng Y, Jiang YH, Xue K, He Z, Van Nostrand JD, Wu L, Yang $Y$, Wang A. Stochastic assembly leads to alternative communities with distinct functions in a bioreactor microbial community. Mbio. 2013;4(2):e00584-612.

26. Yang C, Liu W, He Z, Thangavel S, Wang L, Zhou A, Wang A. Freezing/ thawing pretreatment coupled with biological process of thermophilic Geobacillus sp. G1: acceleration on waste activated sludge hydrolysis and acidification. Bioresour Technol. 2014;175C:509-16.

27. Lozupone C, Knight R. UniFrac: a new phylogenetic method for comparing microbial communities. Appl Environ Microbiol. 2005;71:8228-35.

28. Shannon P, Markiel A, Ozier O, Baliga NS, Wang JT, Ramage D, Amin N, Schwikowski B, Ideker T. Cytoscape: a software environment for integrated models of biomolecular interaction networks. Genome Res. 2003;13:2498-504.

29. Zhou A, Luo H, Varrone C, Wang Y, Liu W, Wang A, Yue X. Enhanced anaerobic digestibility of waste activated sludge by plant-derived biosurfactant. Process Biochem. 2015;50:1413-21.

30. Neyens E, Baeyens J. A review of thermal sludge pre-treatment processes to improve dewaterability. J Hazard Mater. 2003;98:51-67.

31. Rughoonundun H, Mohee R, Holtzapple MT. Influence of carbon-tonitrogen ratio on the mixed-acid fermentation of wastewater sludge and pretreated bagasse. Bioresour Technol. 2012;112:91-7.

32. Montanes R, Solera R, Perez M. Anaerobic co-digestion of sewage sludge and sugar beet pulp lixiviation in batch reactors: effect of temperature. Bioresour Technol. 2015;180:177-84.

33. Wang F, Hidaka T, Sakurai K, Tsumori J. Anaerobic co-digestion of steamtreated Quercus serrata chips and sewage sludge under mesophilic and thermophilic conditions. Bioresour Technol. 2014;166:318-25.

34. Hidaka T, Arai S, Okamoto S, Uchida T. Anaerobic co-digestion of sewage sludge with shredded grass from public green spaces. Bioresour Technol. 2013;130:667-72.

35. Turovskiy IS, Mathai P. Wastewater sludge processing. New Jersey: Wiley; 2006.

36. Zhou A, Du J, Varrone C, Liu W, Wang A. VFAs bioproduction from waste activated sludge by coupling pretreatments with Agaricus bisporus substrates conditioning. Process Biochem. 2014;49:283-9.
37. Batstone D, Keller J, Angelidaki I, Kalyuzhnyi S, Pavlostathis S, Rozzi A, Sanders W, Siegrist H, Vavilin V. The IWA anaerobic digestion model no 1 (ADM1). London: IWA Publishing; 2002.

38. Bertin L, Bettini C, Zanaroli G, Fraraccio S, Negroni A, Fava F. Acclimation of an anaerobic consortium capable of effective biomethanization of mechanically-sorted organic fraction of municipal solid waste through a semi-continuous enrichment procedure. J Chem Technol Biotechnol. 2012;87:1312-9.

39. Wong MT, Zhang D, Li J, Hui RKH, Tun HM, Brar MS, Park T-J, Chen Y, Leung FC. Towards a metagenomic understanding on enhanced biomethane production from waste activated sludge after $\mathrm{pH} 10$ pretreatment. Biotechnol Biofuels. 2013;6:1.

40. Tan R, Miyanaga K, Toyama K, Uy D, Tanji Y. Changes in composition and microbial communities in excess sludge after heat-alkaline treatment and acclimation. Biochem Eng J. 2010;52:151-9.

41. Ueki A, Akasaka H, Suzuki D, Ueki K. Paludibacter propionicigenes gen. nov., sp. nov., a novel strictly anaerobic, Gram-negative, propionateproducing bacterium isolated from plant residue in irrigated rice-field soil in Japan. Int J Syst Evol Microbiol. 2006;56:39-44.

42. Qiu Y-L, Kuang X-Z, Shi X-S, Yuan X-Z, Guo R-B. Paludibacter jiangxiensis sp. nov., a strictly anaerobic, propionate-producing bacterium isolated from rice paddy field. Arch Microbiol. 2014;196:149-55.

43. Ziganshina EE, Belostotskiy DE, Ilinskaya ON, Boulygina EA, Grigoryeva TV, Ziganshin AM. Effect of the organic loading rate increase and the presence of zeolite on microbial community composition and process stability during anaerobic digestion of chicken wastes. Microbiol Ecol. 2015;70:948-60.

44. Grabowski A, Tindall BJ, Bardin V, Blanchet D, Jeanthon C. Petrimonas sulfuriphila gen. nov., sp. nov., a mesophilic fermentative bacterium isolated from a biodegraded oil reservoir. Int J Syst Evol Microbiol. 2005:55:1113-21.

45. Zhang K, Song L, Dong X. Proteiniclasticum ruminis gen. nov., sp. nov., a strictly anaerobic proteolytic bacterium isolated from yak rumen. Int J Syst Evol Microbiol. 2010;60:2221-5.

46. Chen S, Niu L, Zhang Y. Saccharofermentans acetigenes gen. nov., sp. nov., an anaerobic bacterium isolated from sludge treating brewery wastewater. Int J Syst Evol Microbiol. 2010;60:2735-8.

47. Maspolim Y, Zhou Y, Guo C, Xiao K, Ng WJ. The effect of pH on solubilization of organic matter and microbial community structures in sludge fermentation. Bioresour Technol. 2015;190:289-98.

48. Looft T, Levine UY, Stanton TB. Cloacibacillus porcorum sp. nov., a mucindegrading bacterium from the swine intestinal tract and emended description of the genus Cloacibacillus. Int J Syst Evol Microbiol. 2013:63:1960-6.

49. Park KY, Jang HM, Park M-R, Lee K, Kim D, Kim YM. Combination of different substrates to improve anaerobic digestion of sewage sludge in a wastewater treatment plant. Int Biodeterior Biodegrad. 2016;109:73-7.

50. Hong C, Haiyun W. Optimization of volatile fatty acid production with cosubstrate of food wastes and dewatered excess sludge using response surface methodology. Bioresour Technol. 2010;101:5487-93.

51. Peng Y, Ma Y, Wang S. Denitrification potential enhancement by addition of external carbon sources in a pre-denitrification process. J Environ Sci. 2007;19:284-9.

52. Jiang $Y$, Chen $Y$, Zheng $X$. Efficient polyhydroxyalkanoates production from a waste-activated sludge alkaline fermentation liquid by activated sludge submitted to the aerobic feeding and discharge process. Environ Sci Technol. 2009;43:7734-41.

53. Morgan-Sagastume F, Pratt S, Karlsson A, Cirne D, Lant P, Werker A. Production of volatile fatty acids by fermentation of waste activated sludge pre-treated in full-scale thermal hydrolysis plants. Bioresour Technol. 2011;102:3089-97.

54. Lopez-Vazquez CM, Oehmen A, Hooijmans CM, Brdjanovic D, Gijzen HJ, Yuan Z, van Loosdrecht MC. Modeling the PAO-GAO competition: effects of carbon source, pH and temperature. Water Res. 2009:43:450-62.

55. Pijuan M, Saunders A, Guisasola A, Baeza J, Casas C, Blackall L. Enhanced biological phosphorus removal in a sequencing batch reactor using propionate as the sole carbon source. Biotechnol Bioeng. 2004;85:56-67.

56. Feng L, Luo J, Chen Y. Dilemma of sewage sludge treatment and disposal in China. Environ Sci Technol. 2015;49:4781-2. 
57. Yanli Y, Peidong Z, Wenlong Z, Yongsheng T, Yonghong Z, Lisheng W. Quantitative appraisal and potential analysis for primary biomass resources for energy utilization in China. Renew Sust Energ Rev. 2010;14:3050-8.

58. Sedlak R. Phosphorus and nitrogen removal from municipal wastewater: principles and practice. 1991;246:5868-76.
59. Daigger $\mathrm{G}$, Bowen P. Economic considerations on the use of fermenters in biological nutrient removal systems. Use of fermentation to enhance biological nutrient removal. Proceedings of the conference seminar, 67th annual water environment federation conference and exposition. 1994.
Submit your next manuscript to BioMed Central and we will help you at every step:

- We accept pre-submission inquiries

- Our selector tool helps you to find the most relevant journal

- We provide round the clock customer support

- Convenient online submission

- Thorough peer review

- Inclusion in PubMed and all major indexing services

- Maximum visibility for your research

Submit your manuscript at www.biomedcentral.com/submit 